\title{
EXPERIMENTAL AND NUMERICAL PARAMETRIC STUDY OF RESISTANCE SPOT WELDING PROCESS OF AISI 1008 STEEL SHEETS
}

\author{
Ata Khabaz-Aghdam \\ Mechanical Engineering Department, Bu-Ali Sina University, Hamedan, Iran, and \\ Mechanic Group, Bu-Ali Sina University, Hamedan, Iran \\ e-mail: a_khabazaghdam@sut.ac.ir \\ AZHDAR RAHMANI \\ Mechanical Engineering Department, Sahand University of Technology, Sahand New Town, Tabriz, Iran \\ ABBAs FADAei \\ Mechanical Engineering Department, Bu-Ali Sina University, Hamedan, Iran
}

\begin{abstract}
In the present research, a parametric study in Resistance Spot Welding (RSW) of thin AISI 1008 steel sheets is investigated via FEM. All the time steps through the RSW process, including squeeze time, welding time, holding time and cooling time are taken into account. First, the effects of various parameters such as electrical current, welding time and electrode tip diameter are investigated in the nugget geometry. Then, a time history stress diagram and residual stresses are obtained in RSW weldment. FEM results are validated very well by some experiments which were performed in two parts of nugget geometry and residual stresses.
\end{abstract}

Keywords: resistance spot welding, nugget geometry, residual stresses, simulation, experimentation

\section{Introduction}

Resistance Spot Welding (RSW) is the process of joining two or more pieces of metal together by passing electrical current through a relatively small area (spot) while applying pressure for a given amount of time. This method has been used widely because RSW is faster and easier than other welding methods and has automation capability. In the car industry, RSW is utilized for connecting chassis components which are made of thin sheets. Finite Element Method (FEM) provides a good insight into the RSW formation process. So far, several analytical and numerical studies have been performed in the field of RSW. One of the first studies on RSW process was performed by Tsai et al. (1992). They introduced a 2D axisymmetric model to simulate the RSW process and obtained direct correlations between nugget formation and expansion displacement of electrodes. Feulvarch et al. (2004) studied thermal-electrical contact conditions in resistance welding using FEM and derived some results for size of the nugget. Zhang et al. (2008) utilized FE to predict the nugget development during resistance spot welding of galvanised sheet steels. They compared the predicted nugget shape and size with experimental data, and obtained a good agreement. Zhang (2003) introduced a new commercial software for resistance welding simulation. By introducing a two-dimensional model, Zhigang et al. (2006, 2007) analyzed mechanical and thermal behavior of the RSW process using Ansys software. They investigated pressure distribution between contact surfaces of the Sheet-Sheet $(\mathrm{S} / \mathrm{S})$ and Electrode-Sheet (E/S) system as well as stress and strain distribution in the workpiece. Eisazadeh et al. (2010) performed a parametric FE study on the shape and size of the nugget for various effective parameters. Qiu et al. (2010) studied the effect of electrode force of the RSW process 
on magnesium sheets and showed the importance of the electrode force on the performance of welding. Hashemi et al. (2012) also studied a two-dimensional numerical model to investigate the distribution of temperature in RSW. They obtained the effects of welding parameters such as applied voltage and welding cycle on thermal history of the process. Ma and Murakawa (2010) focused on the nugget formation processes under different RSW conditions for three pieces of high strength steel sheets on the real automobile industry. They used the real shape and size of electrodes and real welding conditions in their FEM model. Also, Lei et al. (2011) and Shen et al. (2011) offered a FEM analysis to acquire thermal behavior of the RSW for three sheets. Weld formation and geometry of the nugget were presented in their work. Hassanifard and Zehsaz (2010) numerically simulated the RSW process of 5083-O aluminum alloy using an axisymmetric model of electrodes and sheets. Then they employed the strain-based method for prediction of RSW fatigue life. Eshraghi et al. (2014) introduced a two-dimensional symmetric model using SysWeld to perform some studies on phase changes in Heat Affected Zone (HAZ). Wan et al. (2014), both numerically and experimentally, studied the effect of RSW current on microstructure of the Fusion Zone (FZ) and HAZ. They also examined mechanical performance of welded joints under tensile-shear tests. Hassanifard and Feyzi (2015) developed an analytical model based on integral transformations to predict nugget diameters in resistance spot welding of thick aluminum alloy sheets. Wan et al. (2016) analytically calculated both Electrical Contact Resistance (ECR) and Thermal Contact Resistance (TCR) of Al to zinc coated steel based on analytical formulations. Also, they used the improved ECR and TCR to simulate a two-dimensional axisymmetric finite element model with ANSYS commercial software and obtained a good agreement with experimental results in prediction of the nugget radius.

Due to the coupling of electra thermal and mechanical phenomenon and also nonlinear nature of the material properties, numerical analysis of resistance welding is a complex process. However, numerous and valuable works have been done in the field of RSW simulation, there is lack of studies on the mechanical part containing stresses and mainly residual stresses as well as parametric investigation on the nugget formation. Therefore, in the present study, first, a comprehensive parametric investigation has been performed on the effect of various RSW parameters such as electrical current, welding time and electrode tip diameter on the size and shape of the nugget. Then, residual stresses of RSW thin steel sheets weldments are obtained precisely. It is noteworthy that temperature and stress time history diagrams attained from transient FE simulation results can improve our knowledge about the RSW process.

\section{Materials and methods}

A 2D axisymmetric model is established in ANSYS commercial software. The flowchart shown in Fig. 1 illustrates a step-by-step simulation which is performed in ANSYS Parametric Design Language (APDL). According to the flowchart, first in the squeeze step, the electrodes hold the sheets to make a good contact between faying surfaces. Then, by applying the electrical current in the transient electro-thermal analysis, temperature in the model increases over one time cycle $0.001 \mathrm{~s}$. In the next block, thermo-mechanical analysis performed by considering the nodal temperature results from the previous block and also the electrode force. The loops of electro-thermal and thermo-mechanical analysis are continued until the end of welding time $t_{w}$. Inasmuch as AC current which is used for simulation here, the amount of applied current is updated in every time step. Moreover, because of nonlinear nature of electrodes and sheets properties, all the electrical, thermal and mechanical properties of both electrodes and sheets are updated over time. After the welding time, the holding time $t_{h}$ is commenced. Here, the electrical current is removed while the electrode force remains. At the last time step, the workpiece cools at the room temperature during the cooling time $t_{c}\left(25^{\circ} \mathrm{C}\right)$. Hereby, the whole RSW process will be simulated in the field of heat transfer and stress analysis. 


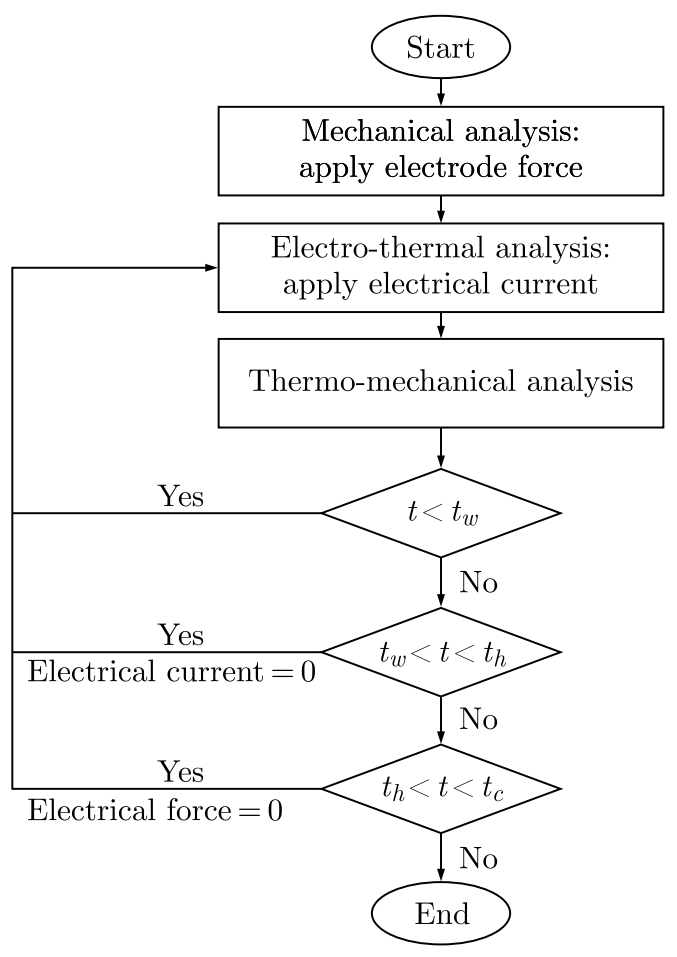

Fig. 1. Step-by-step flowchart of FE simulation of the RSW procedure
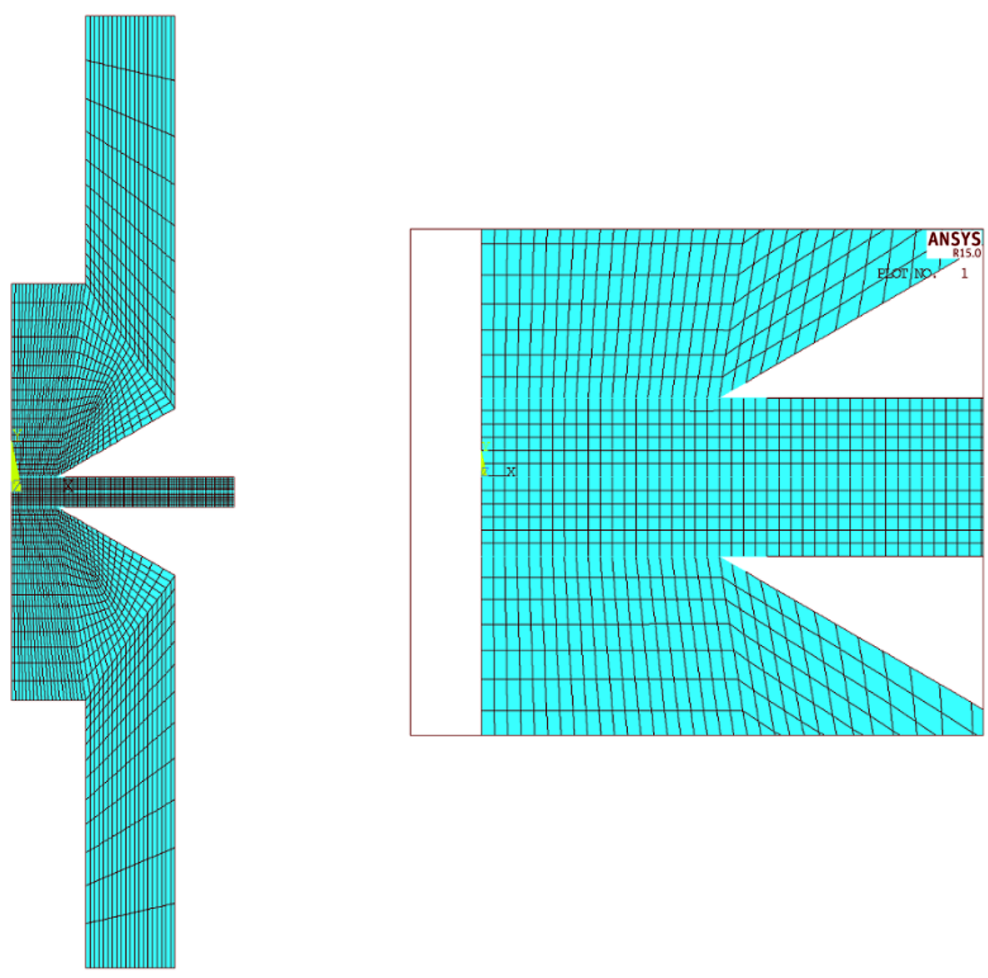

Fig. 2. 2D axi-symmetric model of electrodes and sheets

The electrical, thermal and mechanical properties of AISI 1008 steel plates and copper electrodes are strongly temperature dependent and extracted from ASM (ASM Handbook, 1990). The 2D axisymmetric FE model of RSW consists of two electrodes and two sheets (Fig. 2). Geometry, loading and boundary conditions are symmetric to the vertical axis. As shown in this figure, near the contact region, which is subjected to the highest temperature and stress concentration, smaller elements are used. 
The governing equations of the resistance welding process include electrical, thermal and mechanical fields. Laplace equation (2.1) indicates the steady-state electric potential field of sheets and electrodes

$$
\frac{\partial}{\partial r}\left(\mu \frac{\partial \varphi}{\partial r}\right)+\frac{\partial}{\partial z}\left(\mu \frac{\partial \varphi}{\partial z}\right)+\frac{\mu}{r} \frac{\partial \varphi}{\partial r}=0
$$

where $\varphi$ and $\mu$ are respectively electric potential and electrical conductivity, which is inversion of electrical resistance. Also, $r$ and $z$ are radial and perpendicular axis, respectively. To obtain the temperature distribution in the model, transient heat equation (2.2) must be solved simultaneously with Laplace equation (2.1)

$$
k \frac{1}{r} \frac{\partial}{\partial r}\left(r \frac{\partial T}{\partial r}\right)+k \frac{1}{r} \frac{\partial}{\partial z}\left(r \frac{\partial T}{\partial z}\right)+q_{v}=\rho C \frac{\partial T}{\partial t}
$$

where $\rho, C, k, T$ and $t$ are density, specific heat, conductivity, temperature and time, respectively; and $q_{v}$ is the amount of heat generated per unit volume which is calculated by Joule's equation

$$
q_{v}=R I^{2} t
$$

Equations of the mechanical field are derived from the potential energy functional, as follows

$$
\Pi=\iiint \sigma \varepsilon d V-\iint F v d S
$$

In which $\Pi, v, \varepsilon$ and $\sigma$ are potential energy functional, total displacements, strain and stress, respectively. The first term is related to displacements of the model, and the second term is related to corresponding boundary conditions of surface forces. Figure 3 shows the boundary conditions that are applied in the model of electrodes and sheets. The outer surfaces of electrodes and sheets are chilled by water and air with the welding condition shown in Table 1.

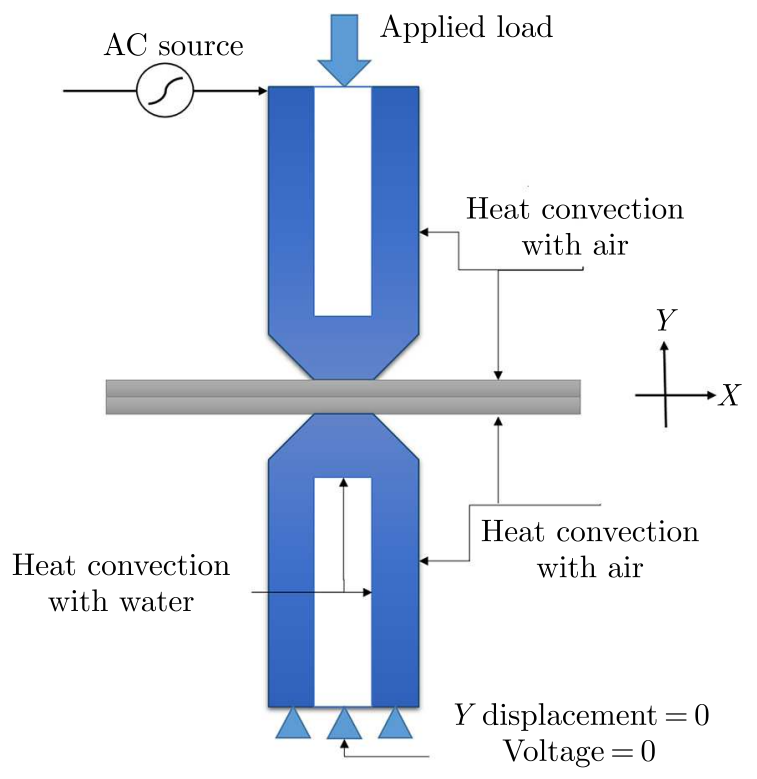

Fig. 3. Boundary conditions

\section{Results and discussion}

Table 2 indicates a comparison of various welding parameters that effect the nugget geometry as well as residual stresses. As shown in Table 2, for examination of the effects of one individual parameter on the weld formation and also residual stresses, changes of one parameter are investigated while the other parameters supposed to be constant. 
Table 1. Welding conditions

\begin{tabular}{|c|c|c|}
\hline & $\begin{array}{c}\text { Temperature } \\
{\left[{ }^{\circ} \mathrm{C}\right]}\end{array}$ & $\begin{array}{c}\text { Convection heat transfer } \\
\text { coefficient }\left[\mathrm{W} /\left(\mathrm{m}^{2}{ }^{\circ} \mathrm{C}\right]\right.\end{array}$ \\
\hline \hline Air & 25 & 21 \\
\hline Water & 25 & 300 \\
\hline
\end{tabular}

Table 2. Comparison of welding parameters

\begin{tabular}{|c|c|c|c|c|}
\hline $\begin{array}{c}\text { Electrode } \\
\text { force[N] }\end{array}$ & $\begin{array}{c}\text { Sheet thickness } \\
{[\mathrm{mm}]}\end{array}$ & $\begin{array}{c}\text { Welding cycle (each } \\
\text { cycle equals 0.02 s) }\end{array}$ & $\begin{array}{c}\text { Electrode tip } \\
\text { diameter }[\mathrm{mm}]\end{array}$ & $\begin{array}{c}\text { Electrical current } \\
{[\mathrm{kA}]}\end{array}$ \\
\hline \hline 2225 & 1 & 10 & 6 & $8.5,9,9.5,10,10.5,11$ \\
\hline 2225 & 1 & 10 & $5,5.5,6,6.5,7,7.5$ & 9.5 \\
\hline 2225 & 1 & $8,9,10,11,12$ & 6 & 9.5 \\
\hline 2225 & 1 & 10 & 6 & 9.5 \\
\hline
\end{tabular}

The nugget shape is the main output of the electrical-thermal analysis. Due to the elliptical shape of the nugget, two characteristic dimensions including the diameter and depth of weld penetration, are used to describe the shape of the nugget. Figure 4 shows the geometry of the RSW cross section. It is noteworthy that the nugget geometry is reckoned with the FZ, where temperature reaches the melting temperature of steel $\left(1530^{\circ} \mathrm{C}\right)$.

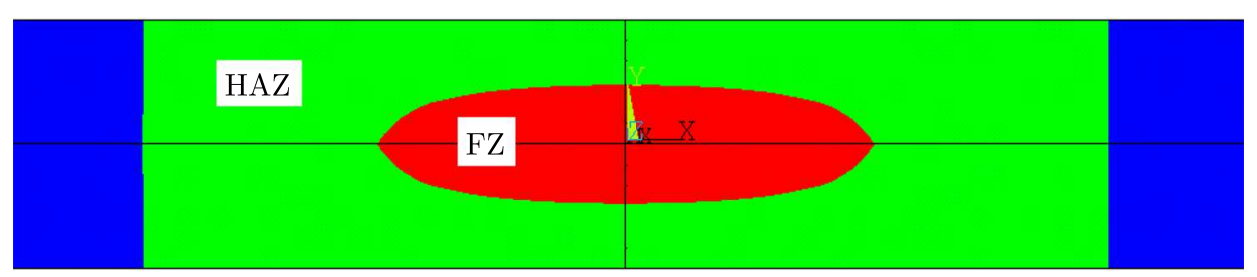

Fig. 4. RSW cross section

According to equation (2.3), the amount of heat generated is linearly related with the welding time. With an increase of heat, the temperature in the HAZ increases and the nugget grows. Figure 5 presents the temperature distribution on the model of electrodes and sheets. This figure shows the nugget formation during the welding time. The welding parameters in this simulation are as follows: electrode diameter $6 \mathrm{~mm}$, electrical current $9 \mathrm{kA}$ and electrode force $2.5 \mathrm{kN}$.

Figure 6 indicates temperature variation in the radial direction ( $x$ axis in Fig. 4); during 8 to 12 cycles (each cycle is $0.02 \mathrm{~s}$ ). By using this figure, the radius of the nugget can be calculated at each time cycle. Whereas, the melting temperature of AISI 1008 steel sheet is equal to $1530^{\circ} \mathrm{C}$. Then for instance, the nugget radius in 12th cycle is about $2.29 \mathrm{~mm}$.

Figure 7 shows temperature variation of the nugget center from ambient temperature $\left(25^{\circ} \mathrm{C}\right)$. Once applying an electrical current in all diagrams, temperature of the nugget center increases quickly. It is noteworthy that the temperature at the beginning of the RSW increases with a high speed; then at the melting temperature of the steel sheets $\left(1530^{\circ} \mathrm{C}\right)$ it remains constant for a short time during the melting process, and after completion of melting it increases again. It can be observed from Fig. 7 for larger electrical currents, the rate of temperature rise in the nugget center is higher. For example, the nugget growth for electrical currents 9 and $11 \mathrm{kA}$ occurs in the 6th and 11th cycle, respectively.

Figure 8 shows the radius of the nugget over the welding time for different welding currents. According to Fig. 8, an increase of the welding current causes the nugget to perform rapidly. The radius of the nugget grows with a high gradient at first and then its growth rate decreases. This is due to the electrical resistance of sheets. Electrical resistance in the RSW process consists of two 

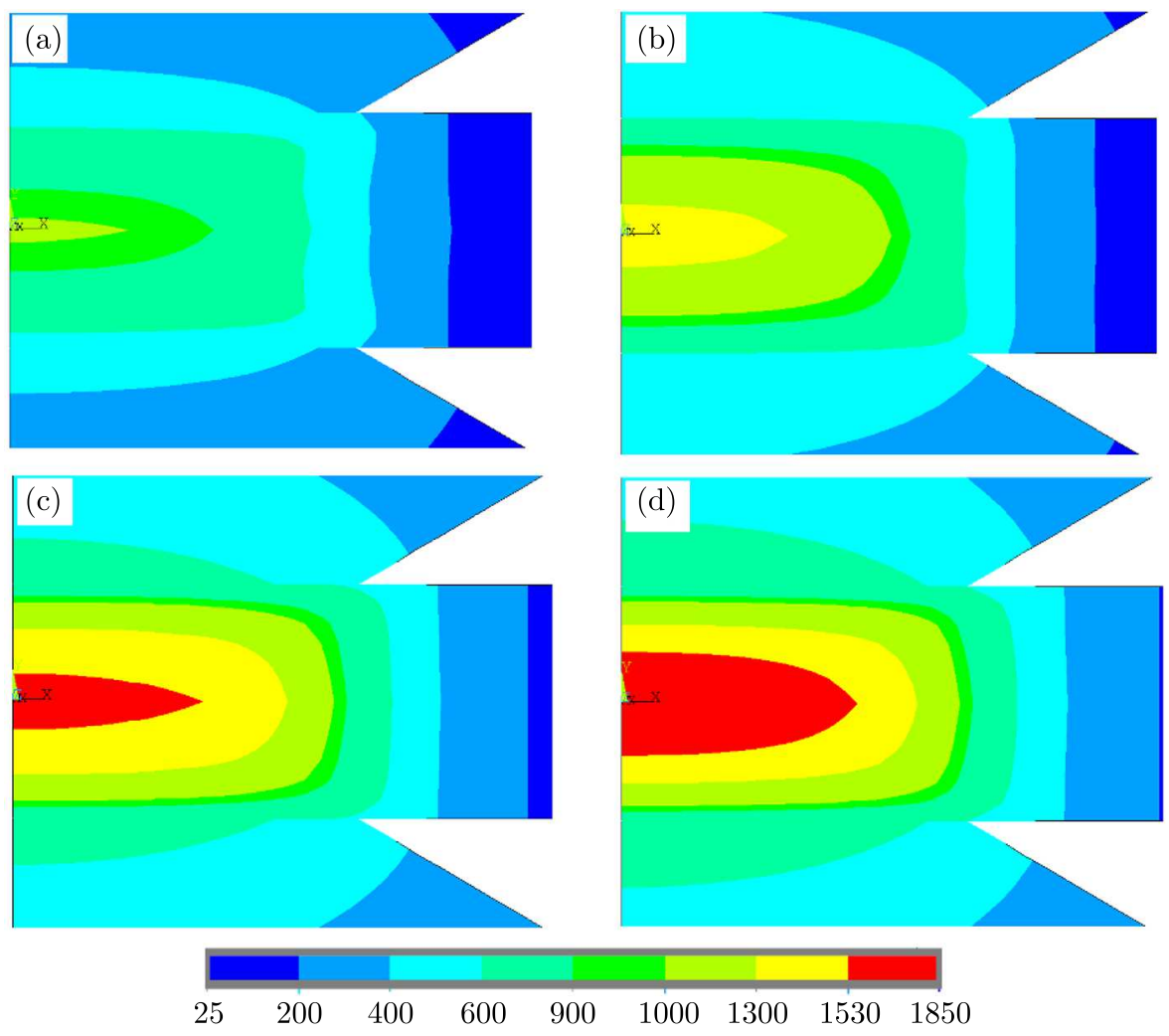

Fig. 5. Temperature distribution on the electrodes and sheets during welding time: (a) $t=0.1 \mathrm{~s}$, (b) $t=0.14 \mathrm{~s}$, (c) $t=0.2 \mathrm{~s}$, (d) $t=0.24 \mathrm{~s}$

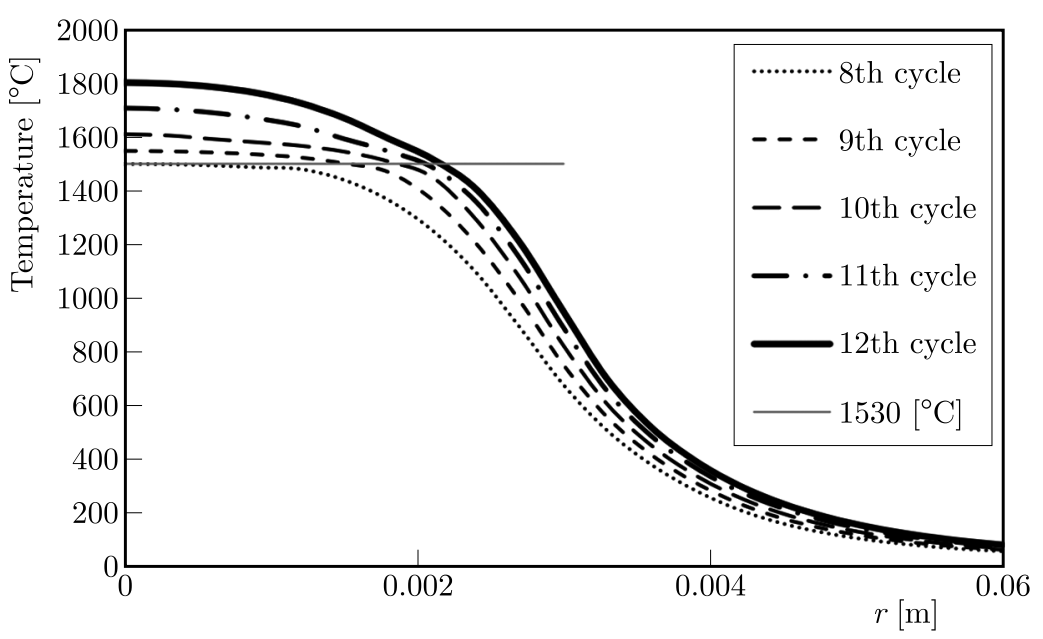

Fig. 6. Temperature variations in the radial direction

parts: the electrical resistance of metal and the electrical contact resistance. At the beginning of the welding cycle, the electrical contact resistance is much higher than the base metal resistance. However, when the two sheets are fused together, this quantity becomes zero and the nugget growth would be only because of its electrical resistance.

Electrode tip diameter is one of the important effective parameters of the quality of the RSW process. By increasing the electrode tip diameter, the contact radius through the E/S and S/S interfaces increases, consequently, significant changes occur in both the nugget shape and the required time to create the desired connection. The maximum temperature in the nugget center is an appropriate parameter for a better understanding of nugget formation during welding. 


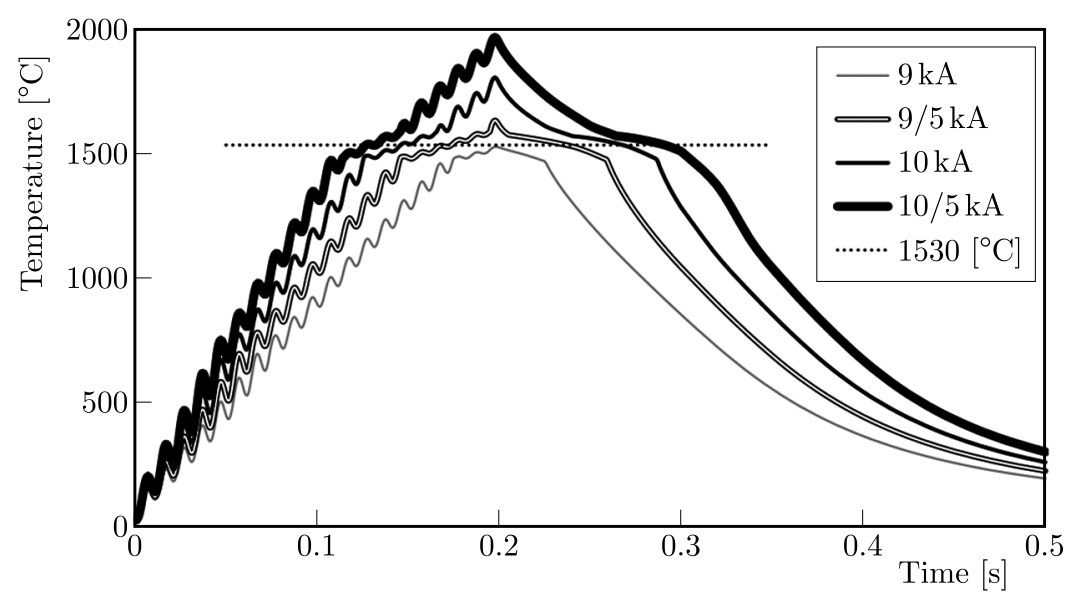

Fig. 7. Temperature of the nugget center for different electrical currents per time

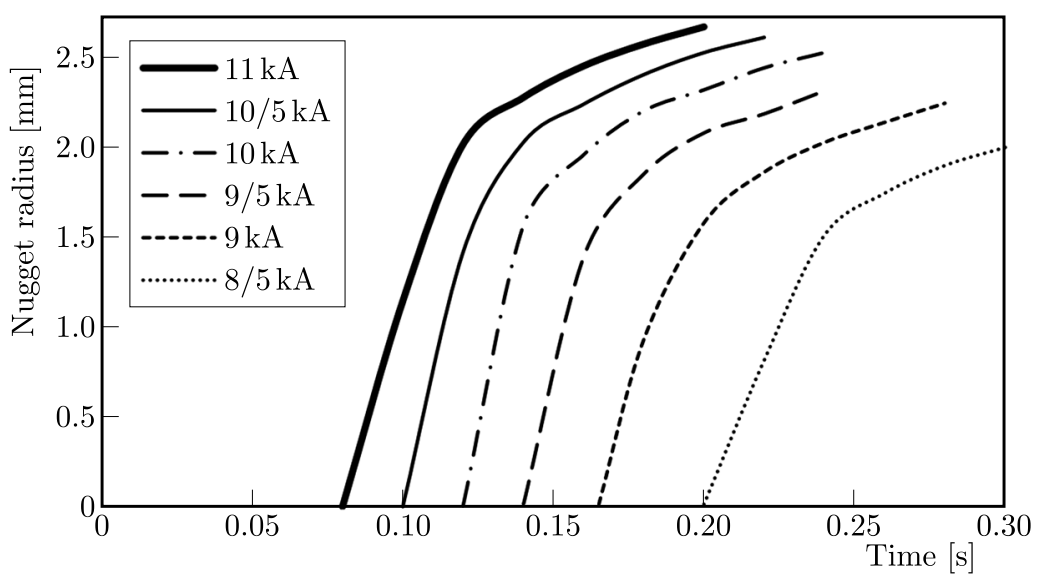

Fig. 8. Nugget radius versus welding time

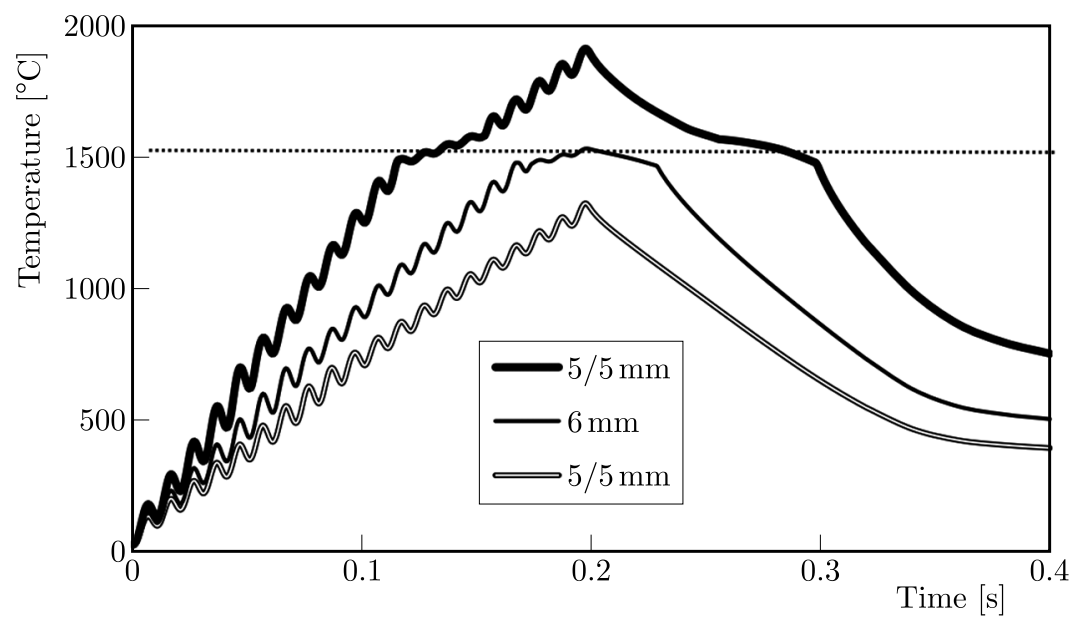

Fig. 9. Temperature of the nugget center during welding time for different electrode tip diameters

Figure 9 illustrates the nugget center temperature during welding time considering different electrode tip diameters. It is shown that nugget formation is delayed by increasing the electrode tip diameter, and it is because of the generated heat spread over a larger E/S and S/S contact areas, therefore, the bigger the electrode diameter leads to a slower rate of temperature.

Nugget radius in different electrode tips is depicted in Fig. 10. From this figure, it can be noticed that by decreasing the diameter of the electrode tip the nugget generates and grows 
more quickly. In other words, the temperature gradient for a smaller electrode tip diameter is higher.

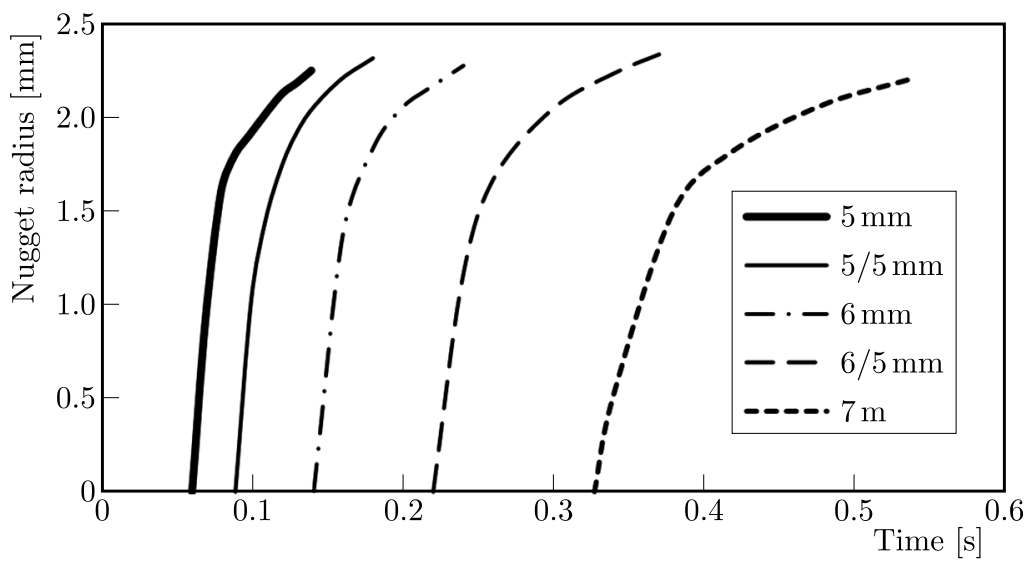

Fig. 10. Nugget radius for different electrode tip diameter

To evaluate the accuracy of the electrical-thermal analysis results, nugget geometry is experimentally tested for three AISI 1008 steel sheets of $1 \mathrm{~mm}$ thickness and compared with the simulation results. The steel sheet dimensions should be sufficiently larger than the diameter of the HAZ to satisfy the 2D axisymmetric condition. Chemical compounds of the used samples and chemical composition of AISI 1008 steel are listed in Table 3. In Table 4, the mechanical properties of the samples, which are determined through tensile testing, are presented with their corresponding values given by Wan et al. (2014).

Table 3. Chemical compounds

\begin{tabular}{|c|c|c|c|c|c|c|}
\hline & $\mathrm{Fe}$ & $\mathrm{C}<$ & $\mathrm{Mn}$ & $\mathrm{Si}$ & $\mathrm{P}$ & $\mathrm{Al}$ \\
\hline \hline AISI 1008 & Base & 0.080 & 0.400 & 0.010 & 0.060 & - \\
\hline Test sample & Base & 0.071 & 0.319 & 0.050 & 0.063 & 0.042 \\
\hline
\end{tabular}

Table 4. Mechanical properties of sheets

\begin{tabular}{|c|c|c|c|}
\hline & $\begin{array}{c}\text { Yield stress } \\
{[\mathrm{MPa}]}\end{array}$ & $\begin{array}{c}\text { Ultimate stress } \\
{[\mathrm{MPa}]}\end{array}$ & $\begin{array}{c}\text { Elongation } \\
{[\%]}\end{array}$ \\
\hline \hline AISI 1008 & 240 & 370 & 29 \\
\hline Test sample & 245 & 380 & 30 \\
\hline
\end{tabular}

A pneumatic spot welding machine equipped with automatic control board for adjusting the welding time and electric current was utilized to fabricate the samples. The samples were cut through the nugget cross section and were photographed by a microscope, and then the nugget radius was measured. Welding parameters of the RSW samples and also calculated FEM and experimental nugget radii are given in Table 5 . The results indicate a good agreement between the numerical simulation and experimental results.

In this Section, mechanical output of the simulations, including the stresses, are discussed. The residual stresses in the weldment are the main output of the mechanical analysis. Figure 11 shows the radial, circumferential and von Mises stresses at the center of two faying sheets over the RSW time steps. As indicated in the figure, both the radial and circumferential stresses are compressive during squeezing. Then, as the electrodes squeeze the sheets, AC current is applied over the welding time $(0 \mathrm{~s} \ll 0.2 \mathrm{~s})$. Therefore, the compressive stresses in the nugget center increase alternatively. Then, at the beginning of the holding time $(0.2 \mathrm{~s} \ll 0.3 \mathrm{~s})$, the current 
Table 5. Nugget radius obtained by FEM solution and experimental results

\begin{tabular}{|c|c|c|c|c|c|c|c|c|}
\hline No. & $\begin{array}{c}\text { Electrical } \\
\text { current } \\
{[\mathrm{kA}]}\end{array}$ & $\begin{array}{c}\text { Electrode } \\
\text { force } \\
{[\mathrm{kN}]}\end{array}$ & $\begin{array}{c}\text { Welding } \\
\text { time } \\
{[\mathrm{cycle}]}\end{array}$ & $\begin{array}{c}\text { Electrode } \\
\text { tip diam. } \\
{[\mathrm{mm}]}\end{array}$ & $\begin{array}{c}\text { Sheet } \\
\text { thickness } \\
{[\mathrm{mm}]}\end{array}$ & $\begin{array}{c}\text { FEM } \\
\text { nugget radius } \\
{[\mathrm{mm}]}\end{array}$ & $\begin{array}{c}\text { Experimental } \\
\text { nugget radius } \\
{[\mathrm{mm}]}\end{array}$ & $\begin{array}{c}\text { Error } \\
{[\%]}\end{array}$ \\
\hline \hline 1 & 9 & 2.5 & 0.24 & 6 & 1 & 2.00 & 1.95 & 2.5 \\
\hline 2 & 9 & 2.5 & 0.20 & 6 & 1 & 1.56 & 1.59 & 1.8 \\
\hline 3 & 9 & 2.5 & 0.30 & 6.5 & 1 & 2.04 & 1.99 & 2.5 \\
\hline 4 & 9 & 2.5 & 0.38 & 7 & 1 & 1.49 & 1.53 & 2.6 \\
\hline
\end{tabular}

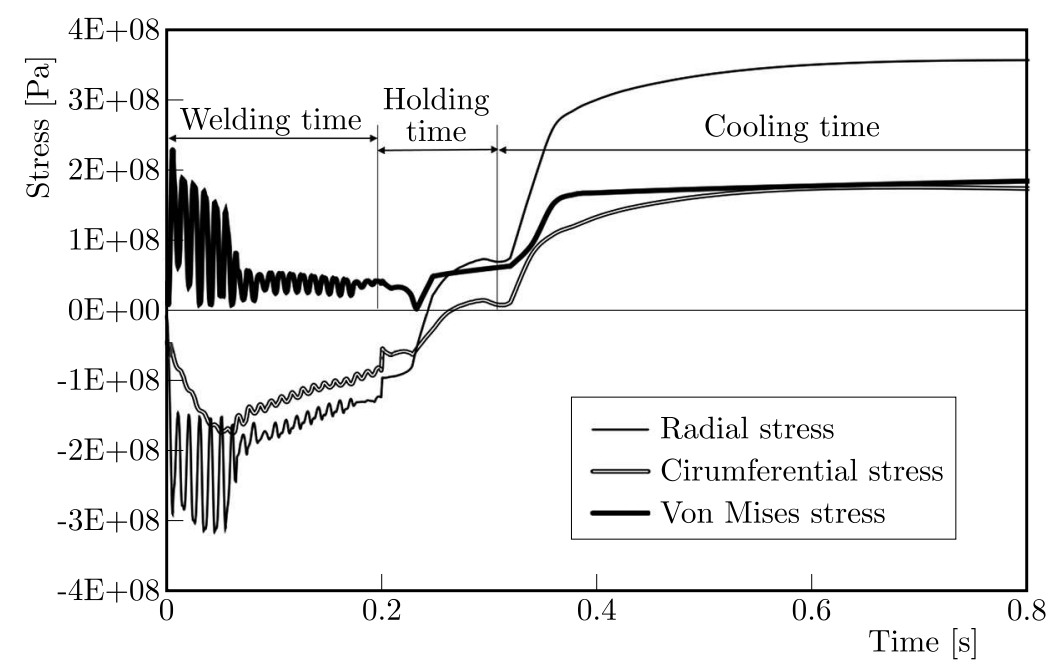

Fig. 11. Radial, tetrahedral and effective von Mises stresses of the nugget center over time. RSW parameters: electrode diameter $6 \mathrm{~mm}$, electrical current $9 \mathrm{kA}$, electrode force $2.5 \mathrm{kN}$, sheet thickness $1 \mathrm{~mm}$, welding time $0.2 \mathrm{~s}$ and holding time $0.1 \mathrm{~s}$

stops, however, the electrodes hold the workpiece and play an important role in heat conduction of the sheets or cool them. Therefore, during the holding time, the stresses are increased instantly; and, compressive stresses are converted to tensile stresses. Finally, at the end of the holding time, the electrodes release the workpiece to chill in the ambient temperature $(>0.3 \mathrm{~s})$. Accordingly, through the cooling period, the tensile stresses rise and then relax to their constant value. The stable magnitude of stresses at the end of the cooling time is considered as the residual stress. Figures 12 and 13 indicate the radial and circumferential stresses, respectively, at the end of the welding time, at 20 times magnification. As shown in these figures, at the end of the welding time, the radial and circumferential stresses in the FZ and HAZ domain are compressive, however, out of the HAZ domain, tensile stresses are observed.

Through the cooling time, the outer surfaces of the sheets are chilled and condensed by the air. Therefore, tensile residual stresses are generated in the FZ domain, however, in distant parts of the HAZ and also in the contact surfaces of the E/S, compressive residual stresses appear. Figures 14, 15 and 16 show the radial, circumferential and von Mises residual stresses, respectively, at the end of the cooling time.

Here, the simulation residual stresses are compared with the hole drilling method. Hole drilling is a semi-nondestructive method, and is mainly used for measuring residual stresses through thickness. To examine reliability of the experimental tests, three same samples of resistance spot welded sheets were made. To prepare the samples for the drilling test, their surfaces were polished completely by a sanding sheet. Then, strain gauges were glued at the top of the smoothed surface of the weld center and the drilling process through the thickness was performed in 9 steps at intervals of $0.1 \mathrm{~mm}$ (form $0.1 \mathrm{~mm}$ to $0.9 \mathrm{~mm}$ of sheet depth). Figure 17 shows the equipment of 


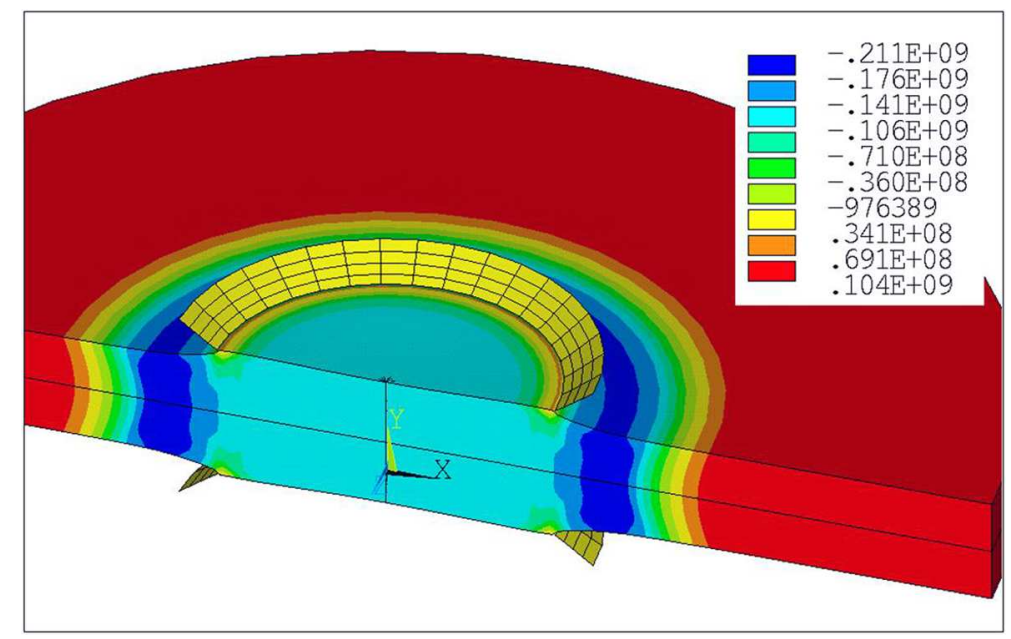

Fig. 12. Radial stresses at the end of the welding time

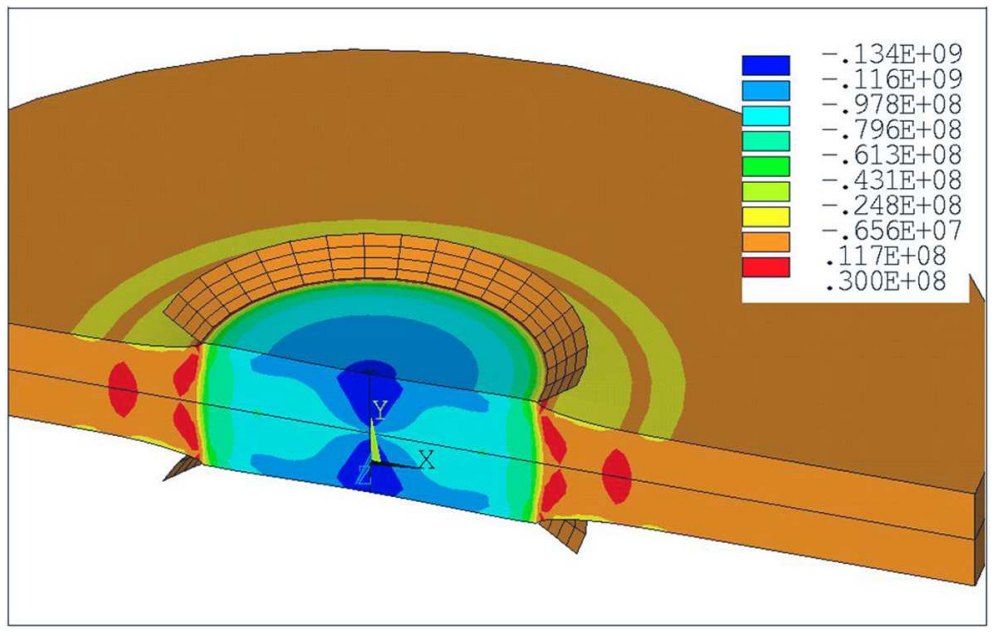

Fig. 13. Circumferential stresses at the end of the welding time

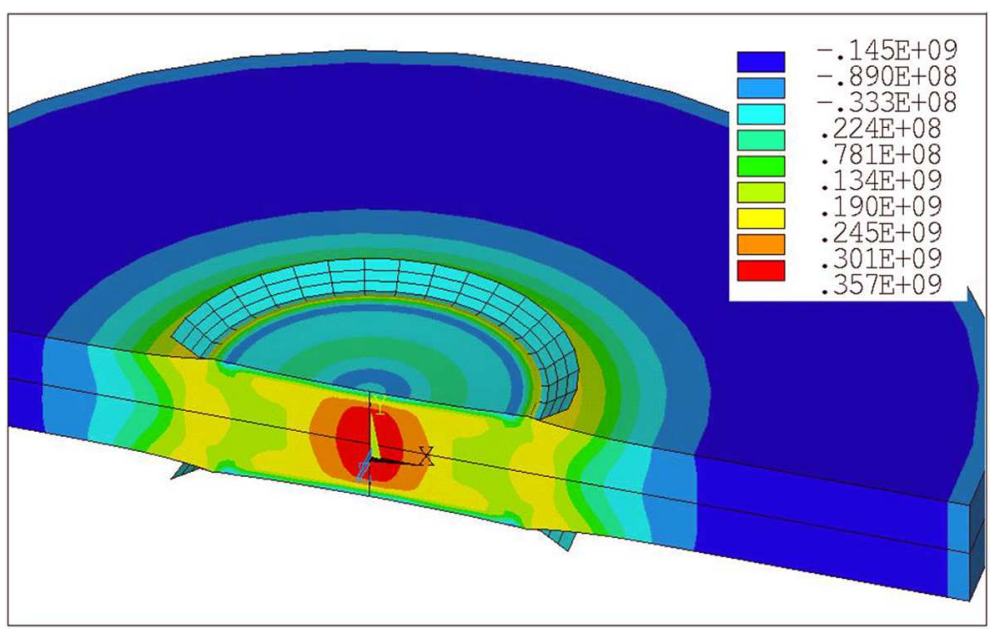

Fig. 14. Radial stresses at the end of the cooling time 


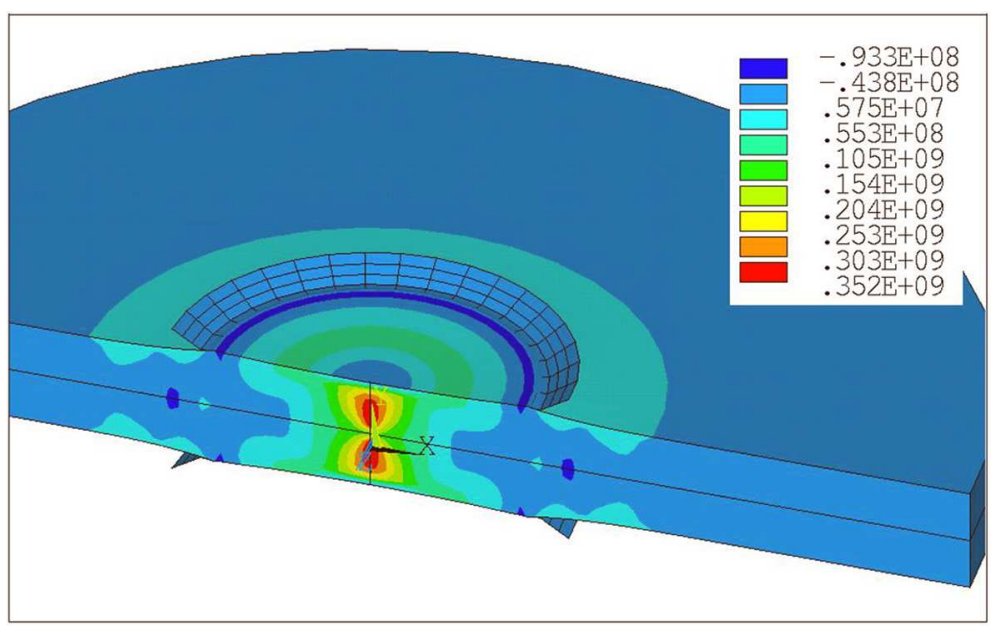

Fig. 15. Circumferential stresses at the end of the cooling time

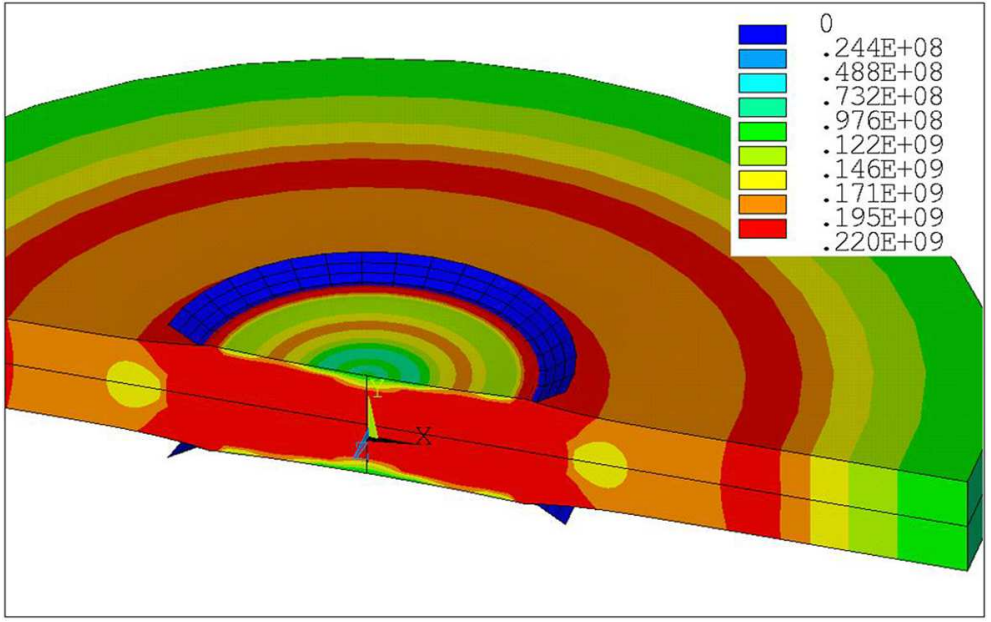

Fig. 16. Von Mises stresses at the end of the cooling time

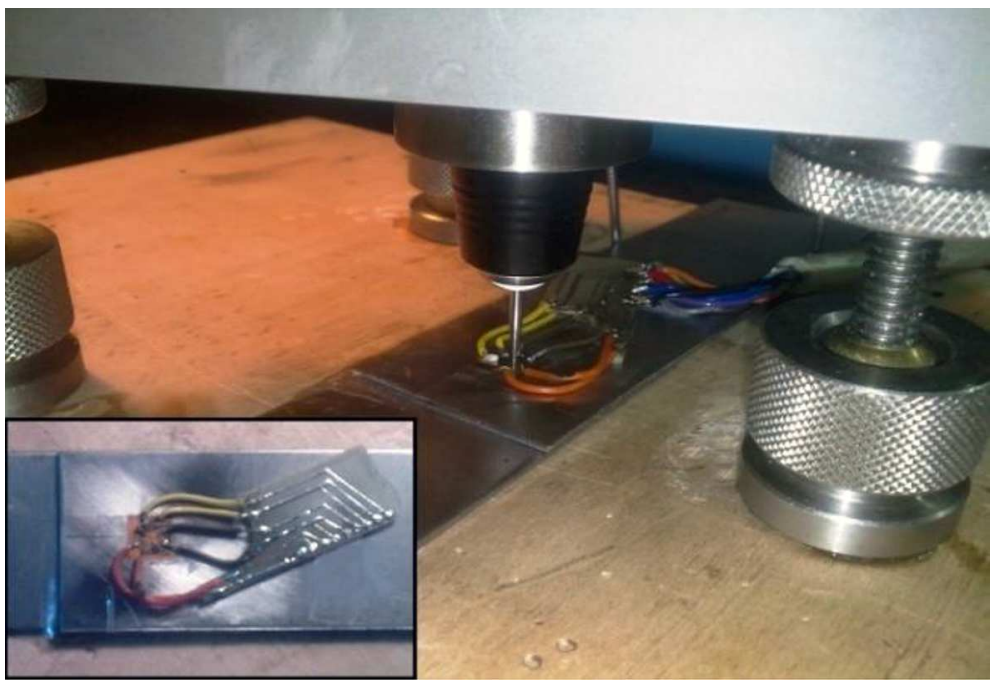

Fig. 17. Hole drilling test of the welded sheets 
the hole drilling strain gauge method for residual stress measurement. Radial and circumferential residual stresses of the FEM and tested samples are shown in Figs. 18 and 19, respectively. Dashed lines in Figs. 18 and 19 give the average residual stresses of three distinct experimented samples. It can be seen from these two figures that at a descending rate, the residual stresses continuously increase from the workpiece surface until the nugget center. Figures 18 and 19 indicate a good agreement between the simulation and experimental results.

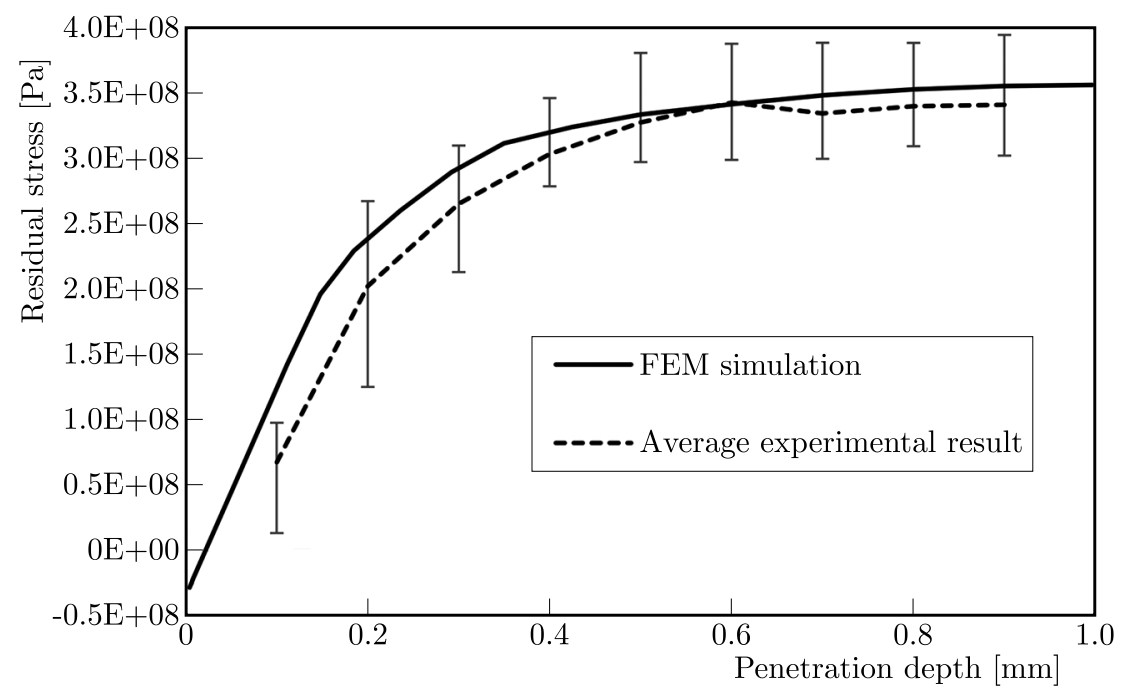

Fig. 18. Residual stresses through thickness of the workpiece

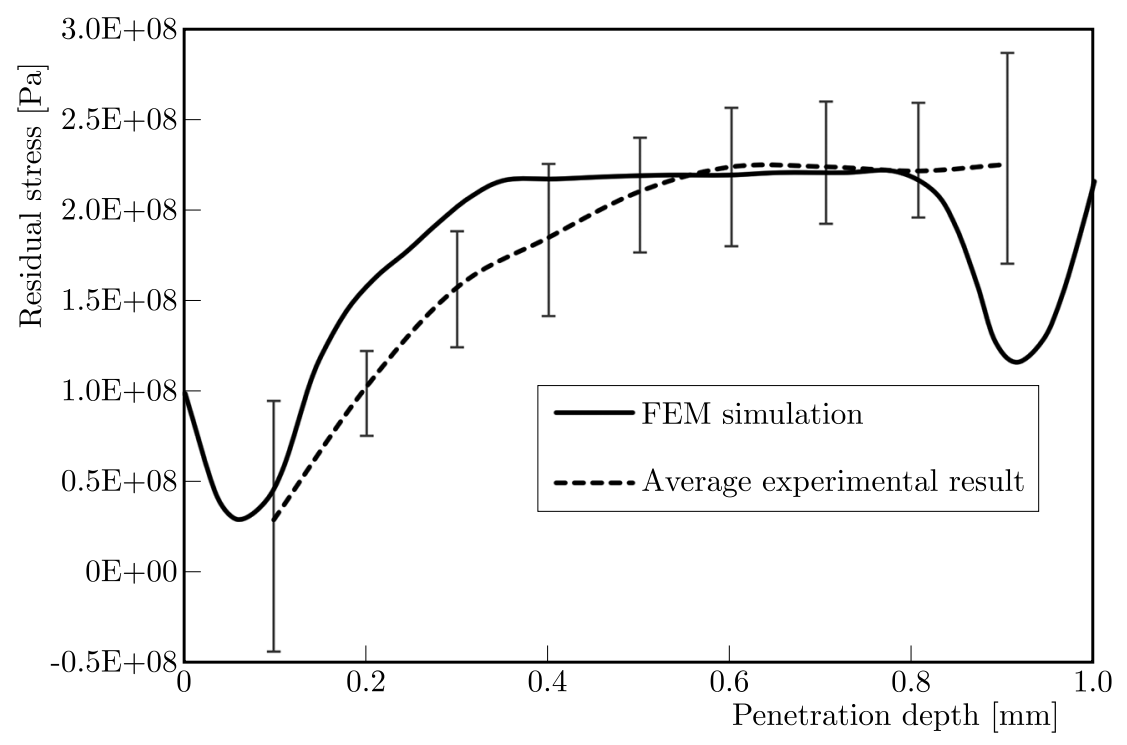

Fig. 19. Circumferential stresses through thickness of the workpiece

\section{Conclusions}

In this research, a parametric study on RSW is performed to investigate the effects of various parameters on weldability of AISI 1008 steel sheets. Nugget shape and residual stresses in the FZ and HAZ domain were calculated numerically by FEM and verified experimentally. Based on this study, the following can be concluded:

- By increasing the electrode diameter, higher electrical current or more welding time will be required to make the nugget of the same size. 
- During the welding, all stresses on the weldment are compressive; and this is due to the high temperature region that is squeezed by electrodes.

- Electrodes have a significant role in the sheets cooling during the holding time, and it causes a high stress gradient in this region.

- After cooling of the weldment, tensile residual stresses are generated in the FZ and HAZ. However, in distant parts of the HAZ, and also in the contact surfaces of the E/S, compressive residual stresses are observed.

- Hole drilling is an effective method for estimating the residual stresses through thickness of the welded sheets.

\section{References}

1. ASM Handbook (formerly 10th ed. and metal handbook), 1990, Properties and selection: nonferrous alloys and special-purpose materials, vol. 2, ASM International, 19-20

2. Eisazadeh H., Hamedi M., Halvaee A., 2010, New parametric study of nugget size in resistance spot welding process using finite element method, Materials and Design, 31, 149-157, DOI: 10.1016/j.matdes.2009.06.042

3. Eshraghi M., Tschopp A., Zaeem M., Felicelli D., 2014, Effect of resistance spot welding parameters on weld pool properties in a DP600 dual-phase steel: A parametric study using thermomechanically-coupled finite element analysis, Materials and Design, 56, 387-397, DOI: 10.1016/j.matdes.2013.11.026

4. Feulvarch E., Robin V., Bergheau J.M., 2004, Resistance spot welding simulation: a general finite element formulation of electrothermal contact conditions, Journal of Materials Processing Technology, 153-154, 436-441, DOI: 10.1016/S0924-0136(04)00417-0

5. Hashemi R., Pashazadeh H., Hamedi M., 2012, An incrementally coupled thermo-electro-mechanical model for resistance spot welding, Materials and Manufacturing Processes, 27, 12, 1442-1449, DOI: 10.1080/10426914.2012.718470

6. Hassanifard S., Feyzi M., 2015, Analytical solution of temperature distribution in resistance spot welding, Journal of Mechanical Science and Technology, 29, 2, 777-784, DOI: 10.1007/s12206015-0139-5

7. Hassanifard S., Zehsaz M., 2010, The effects of residual stresses on the fatigue life of 5083-O aluminum alloy spot welded joints, Procedia Engineering, 2, 1077-1085, DOI: 10.1016/j.proeng.2010.03.116

8. Lei Z., KANG H.T., LiU Y., 2011, Finite element analysis for transient thermal characteristics of resistance spot welding process with three sheets assemblies, Procedia Engineering, 16, 622-631, DOI: $10.1016 /$ j.proeng.2011.08.1133

9. Ma N., Murakawa H., 2010, Numerical and experimental study on nugget formation in resistance spot welding for three pieces of high strength steel sheets, Journal of Materials Processing Technology, 210, 2045-2052, DOI: 10.1016/j.jmatprotec.2010.07.025

10. Qiu R., Shi H., Yu H., Zhang K., Tu Y., Satonaka S., 2010, Effects of electrode force on the characteristic of magnesium alloy joint welded by resistance spot welding with cover plates, Materials and Manufacturing Processes, 25, 11, 1304-1308, DOI: 10.1080/10426914.2010.505619

11. Shen J., Zhang Y., Lai X., Wang P.C., 2011, Modeling of resistance spot welding of multiple stacks of steel sheets, Materials and Design, 32, 550-560, DOI: 10.1016/j.matdes.2010.08.023

12. Tsai C.L., Jammal O.A., Dickinson D.W., 1992, Modeling of resistance spot weld nugget growth, Weld Journal, 71, 2, 47s-54s, DOI: 10.4271/900738

13. Wan X., Wang Y., Zhang P., 2014, Modelling the effect of welding current on resistance spot welding of DP600 steel, Journal of Materials Processing Technology, 214, 2723-2729, DOI: 10.1016/j.jmatprotec.2014.06.009 
14. Wan Z., Wang H.P., Wang M., Carlson B.E., Sigler D.R., 2016, Numerical simulation of resistance spot welding of $\mathrm{Al}$ to Zinc-coated steel with improved representation of contact interactions, International Journal of Heat and Mass Transfer, 101, 749-763, DOI: 10.1016/j.ijheatmasstransfer.2016.05.023

15. ZhANG W., 2003, Design and implementation of software for resistance welding process simulations, Society of Automotive Engineers, Technical Paper 01-0978, 105-113, DOI: 10.4271/2003-01-0978

16. Zhang Y.S., XU J., LAI X.M., Chen G.L., 2008, Numerical simulation of spot welding for galvanised sheet steels, Science and Technology of Welding and Joining, 13, 192-198, DOI: $10.1179 / 174329307 X 249298$

17. Zhigang H., Kim I.S., Wang Y., Li C., Chen C., 2007, Finite element analysis for the mechanical features of resistance spot welding process, Journal of Materials Processing Technology, 185, 160-165, DOI: 10.1016/j.jmatprotec.2006.03.143

18. Zhigang H., Yuanxun W., Chunzhi L., Chuanyao L., 2006, A multi-coupled finite element analysis of resistance spot welding process, Acta Mechanica Solida Sinica, 19, 1, 86-94, DOI: $10.1007 / \mathrm{s} 10338-006-0610-\mathrm{z}$ 